\title{
Means of transportation to work and overweight and obesity: A population-based study in southern Sweden
}

\author{
Martin Lindström* \\ Department of Clinical Sciences, Malmö University Hospital, Lund University, S-205 02 Malmö, Sweden
}

Available online 17 July 2007

\begin{abstract}
Objectives. To investigate the association between means of transportation to work and overweight + obesity and obesity.

Methods. The 2004 public health survey in Skåne is a cross-sectional postal questionnaire study of the population aged 18-80 with a 59\% response rate including 16,705 employed participants.

Results. Forty-six percent of men and $26.6 \%$ of women were overweight (BMI 25.0-29.9); $11.6 \%$ of men and $10.3 \%$ of women were obese (BMI 30.0-); $18.2 \%$ of men and $25.9 \%$ of women bicycled and/or walked to work and $10.4 \%$ and $16.2 \%$ used public transportation, respectively. In contrast, $68.3 \%$ of men and $55.8 \%$ of women went to work by car. The odds ratios of overweight + obesity among persons who walked or bicycled were significantly lower and remained 0.62 (95\% CI 0.51-0.76) among men and 0.79 (95\% CI 0.67-0.94) among women in the models including all confounders compared to the car driving reference category. The odds ratios of obesity were initially significantly lower among both men and women who walked or bicycled, but in the final models only among women. The odds ratios of overweight + obesity as well as obesity were also lower among men using public transportation.

Conclusions. Walking and bicycling to work are significantly negatively associated with overweight + obesity and, to some extent, obesity. Public transportation is significantly negatively associated with overweight + obesity and obesity among men.
\end{abstract}

(C) 2007 Elsevier Inc. All rights reserved.

Keywords: Overweight; Obesity; Means of transportation to work; Sweden

\section{Introduction}

Obesity is a growing health problem in many countries including Sweden (National Public Health Report, 2005; Gregg et al., 2005). In Sweden the risk of overweight and obesity varies according to age, country of birth and socioeconomic status (Lindström et al., 2003; National Public Health Report, 2005). Obesity and overweight are dependent on the balance between energy intake and energy expenditure (Flegal et al., 2002). Increased caloric intake with readily available food and larger portions with high fat and caloric content contributes to the increase in obesity (Young and Nestle, 2002). The relative importance of physical activity at work has decreased in recent decades with a corresponding increase in the relative importance of leisure time physical activity (National Public Health Report, 2005).

\footnotetext{
* Fax: +46 40336215 .

E-mail address: martin.lindstrom@smi.mas.lu.se.
}

Commuting to work is an important structural pre-condition and possibility for regular physical activity in the form of daily walking or bicycling. Bicycling and walking to work increases bodily energy expenditure and decreases the expenditure of fossil energy. Commuting to work by public transportation (bus/ train) may plausibly also decrease expenditure of fossil energy. There is also evidence that persons who commute by public transportation walk substantial distances to and within bus and railway stations (Besser and Dannenberg, 2005). Bicycling, walking and public transportation may thus be recommended as means of transportation to work.

Still, driving by private car to work is the dominant mode of commuting in most developed countries (Wen et al., 2006). Areas characterized by high dependence on car transportation for work, school, shopping and leisure activities is a crucial determinant of physical inactivity, overweight and obesity (Sherwood and Jeffery, 2000; Frank, 2000; Berrigan and Troiano, 2002). In China ownership of a motor vehicle is associated with weight gain and increased risk of obesity (Bell et al., 2002). In the USA more time spent in a car increases the likelihood of developing obesity (Frank 
et al., 2004). Research on obesity and housing patterns suggests that there are higher levels of obesity in communities where the private car is the dominant means of transportation (Craig et al., 2002; Eyler et al., 2003; Saelens et al., 2003; Lopez-Zetina et al., 2006). A recent Australian study found that driving a private car to work was significantly associated with being overweight or obese, with an adjusted odds ratio 1.13 (95\% CI 1.01-1.27, $p=0.047$ ) (Wen et al., 2006). Still, the knowledge concerning the relationship between overweight and obesity, and means of transportation to work is scarce. There is thus a need of more exploratory studies.

The hypothesis of this exploratory study is that walking and/ or bicycling as well as using public transportation to work would be expected to be associated with a significantly decreased risk of overweight and obesity in the investigated population in southern Sweden.

The aim of this study is to investigate the association between means of transportation to work and overweight + obesity (BMI 25.0-) and obesity (BMI 30.0-).

\section{Study design and setting}

\section{Study design}

Data from the cross-sectional 2004 public health survey in Skåne in southern Sweden were used.

\section{Study population}

A postal questionnaire was sent out to a random sample of 47,621 persons living in Skåne aged 18-80 years during the autumn of 2004. Two letters of reminder were sent to the respondents, and a subsequent phone call was made to the remaining non-respondents. A total of 27,963 persons responded, which yields a 59\% response rate. The random sample was weighted by age, sex and geographic area in order to increase the statistical power in some smaller administrative areas. In the statistical calculations of this study this has been corrected by a weight variable, so that the representative prevalences $(\%)$ for the entire Skåne region are given. The differences in prevalences between the uncorrected and corrected data are very small. In this study 16,705 persons reporting some form of current employment on the labour market were included, which is the reason why only a small proportion of persons aged 65 years or above is included.

\section{Assessment of variables}

\section{Outcome variable}

BMI (body mass index) was calculated as $\mathrm{kg} / \mathrm{m}^{2}$ from self reported height $(\mathrm{cm})$ and weight $(\mathrm{kg})$ in the questionnaire. Underweight was defined as BMI $<18.5$ (only Table 1 ), normal weight as BMI 18.5-24.9, overweight as BMI 25.0-29.9 and obesity as BMI $30.0-$. In Tables 2-4, the odds ratios of overweight + obesity (BMI 25.0-) and obesity were calculated dichotomized against underweight and normal weight, and underweight, normal weight and overweight, respectively.
Table 1

Prevalences (\%) of the body mass index, demographic, education, time for travel to work and means of transportation variables

\begin{tabular}{llll}
\hline & $\begin{array}{l}\text { Men } \\
(n=7955)\end{array}$ & $\begin{array}{l}\text { Women } \\
(n=8750)\end{array}$ & $\begin{array}{l}\text { Total } \\
(n=16,705)\end{array}$ \\
\hline Body mass index & & & \\
$\quad-18.49$ & 0.5 & 1.8 & 1.2 \\
18.50-24.99 & 41.9 & 61.3 & 52.0 \\
25.00-29.99 & 46.0 & 26.6 & 35.9 \\
30.0- & 11.6 & 10.3 & 10.9 \\
(Missing) & $(137)$ & $(220)$ & $(357)$ \\
Age & & & \\
18-24 & 5.5 & 5.8 & 5.7 \\
25-34 & 18.4 & 20.3 & 19.4 \\
35-44 & 24.4 & 25.6 & 25.1 \\
45-54 & 25.3 & 25.2 & 25.2 \\
55-64 & 23.8 & 22.1 & 22.9 \\
65-80 & 2.6 & 0.9 & 1.7 \\
(Missing) & $(0)$ & $(0)$ & $(0)$ \\
Country of origin & & & \\
Sweden & 90.1 & 90.1 & 90.1 \\
Other countries & 9.9 & 9.9 & 9.9 \\
(Missing) & $(406)$ & $(277)$ & $(683)$ \\
Education & & & \\
13 years & 35.8 & 46.2 & 41.2 \\
10-12 years & 24.5 & 22.3 & 23.4 \\
-9 years & 39.7 & 31.5 & 35.4 \\
(Missing) & $(531)$ & $(782)$ & $(1313)$ \\
Time for travel to work (one way) & & & \\
Less than 15 min & 38.8 & 41.8 & 40.4 \\
15 min or more & 61.2 & 58.2 & 59.6 \\
(Missing) & $(878)$ & $(794)$ & $(1672)$ \\
Means of transportation & & & \\
Car & 68.3 & 55.8 & 61.7 \\
Walking/bicycling & 18.2 & 25.9 & 22.2 \\
Public transportation & 10.4 & 16.2 & 13.5 \\
Other & 3.1 & 2.1 & 2.6 \\
(Missing) & $(782)$ & $(734)$ & $(1516)$ \\
\hline
\end{tabular}

$N=16,705$.

The Public Health Survey in Skåne, 2004.

\section{Explanatory variables}

Age was divided into six age intervals $18-24,25-34,35-$ $44,45-54,55-64$ and $65-80$ years.

All analyses were stratified by sex.

Country of origin. All persons born in countries other than Sweden were merged into a single category, which yielded the two categories "Sweden" and "other".

Education was divided by length of education into 9 years or less, 10-12 years and 13 or more years of education.

Time for travel to work (one way) was assessed with the alternatives less than $15,15-30$ and 30-60 min and 1-1.5 h, 1.5-2 $\mathrm{h}$ and more than $2 \mathrm{~h}$. It was dichotomized as less than $15 \mathrm{~min}$ and $15 \mathrm{~min}$ or more.

Means of transportation to work was assessed with the alternatives walking, bicycling, car, bus, train and other. It was possible to tick several alternatives. Walking and/or bicycling were defined as one category. Car (only) was defined as one category, bus and/or train as one category and all other combinations as the fourth category (see Appendix A). 
Table 2

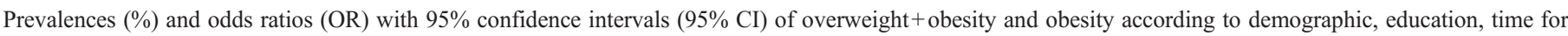
travel to work (one way) and means of transportation to work variables

\begin{tabular}{|c|c|c|c|c|}
\hline & \multicolumn{2}{|c|}{ Overweight + obesity } & \multicolumn{2}{|c|}{ Obesity } \\
\hline & $\%$ & OR $(95 \% \mathrm{CI})$ & $\%$ & OR $(95 \% \mathrm{CI})$ \\
\hline \multicolumn{5}{|l|}{ Age } \\
\hline $18-24$ & 30.5 & 1.00 & 6.3 & 1.00 \\
\hline $25-34$ & 46.7 & $1.99(1.58-2.50)$ & 8.6 & $1.39(0.91-2.14)$ \\
\hline $35-44$ & 59.5 & $3.34(2.67-4.18)$ & 12.3 & $2.08(1.38-3.14)$ \\
\hline $45-54$ & 62.6 & $3.81(3.04-4.77)$ & 12.1 & $2.05(1.36-3.10)$ \\
\hline $55-64$ & 64.8 & $4.18(3.33-5.24)$ & 14.0 & $2.42(1.61-3.65)$ \\
\hline $65-80$ & 60.6 & $3.50(2.46-4.99)$ & 11.9 & $2.01(1.12-3.61)$ \\
\hline (Missing) & (137) & & $(137)$ & \\
\hline \multicolumn{5}{|l|}{ Country of origin } \\
\hline Sweden & 57.4 & 1.00 & 11.8 & 1.00 \\
\hline Other countries & 61.1 & $1.17(1.00-1.36)$ & 10.9 & $0.92(0.72-1.17)$ \\
\hline (Missing) & $(531)$ & & $(531)$ & \\
\hline \multicolumn{5}{|l|}{ Education } \\
\hline 13 years & 50.1 & 1.00 & 7.2 & 1.00 \\
\hline $10-12$ years & 54.4 & $1.19(1.06-1.35)$ & 11.0 & $1.58(1.28-1.95)$ \\
\hline-9 years & 66.0 & $1.93(1.73-2.15)$ & 15.4 & $2.33(1.96-2.79)$ \\
\hline (Missing) & $(653)$ & & $(653)$ & \\
\hline \multicolumn{5}{|c|}{ Time for travel to work (one way) } \\
\hline Less than $15 \mathrm{~min}$ & 57.3 & 1.00 & 11.8 & 1.00 \\
\hline 15 min or more & 58.3 & $1.01(0.91-1.18)$ & 11.4 & $0.96(0.83-1.11)$ \\
\hline (Missing) & $(988)$ & & $(988)$ & \\
\hline \multicolumn{5}{|l|}{ Means of transportation } \\
\hline Car & 61.2 & 1.00 & 12.6 & 1.00 \\
\hline Walking/bicycling & 50.1 & $0.65(0.58-0.73)$ & 9.9 & $0.77(0.63-0.93)$ \\
\hline Public transportation & 49.4 & $0.58(0.50-0.68)$ & 8.1 & $0.56(0.43-0.74)$ \\
\hline Other & 58.6 & $0.85(0.66-1.10)$ & 11.6 & $0.83(0.56-1.24)$ \\
\hline (Missing) & $(894)$ & & $(894)$ & \\
\hline
\end{tabular}

$N($ men $)=7955$.

The Public Health Survey in Skåne, 2004.

\section{Data analysis}

Prevalences (\%) stratified by sex of the body mass index, demographic, education, time for travel to work (one way) and means of transportation variables were calculated (Table 1). Prevalences (\%) and crude odds ratios with 95\% confidence intervals (OR, 95\%) were calculated in order to analyse associations between the demographic, socioeconomic, time for travel to work (one way) and means of transportation variables (with car as reference category) and overweight + obesity and obesity (Tables 2 and 3). Multivariate analyses were conducted using a logistic regression model to assess the potential importance of various confounders (age, country of origin, education and time for travel to work), successively introduced in the models, on the relationship between means of transportation and overweight + obesity and obesity (Table 4 ). All data were analyzed with the SPSS statistical software package (Norusis, 2000).

\section{Results}

Table 1 shows that $0.5 \%$ of the men and $1.8 \%$ of the women were underweight. The proportion with normal weight was $41.9 \%$ among men and $61.3 \%$ among women. The proportions with overweight and obesity were $46.0 \%$ and $11.6 \%$ among men, respectively. The corresponding proportions among women were $26.6 \%$ and $10.3 \%$. The low proportions of persons aged 65 years and above are due to the fact that only persons still employed on the labour market in the active work force were included in this study. Most respondents 65 or above were thus excluded. Almost $10 \%$ of the respondents were born in other countries than Sweden. The prevalence of high education was $35.8 \%$ among men and $46.2 \%$ among women. The proportion with 9 years of education or less was higher among men than among women $(39.7 \%$ compared to $31.5 \%)$. The proportions with less than 15 min travel to work were $38.8 \%$ among men and $41.8 \%$ among women. An $18.2 \%$ proportion of the men and $25.9 \%$ of the women walked/bicycled to work, while $10.4 \%$ of the men and $16.2 \%$ of the women used public transportation. In contrast, $68.3 \%$ of the men and $55.8 \%$ of the women went to work every day by car.

Tables 2 and 3 show that the odds ratios of overweight + obesity $(\mathrm{BMI}=25.0$ and above) were significantly lower among the young, the highly educated and those who walked and bicycled to work among both men and women, but also among men born in Sweden and men who used public transportation. The odds ratios of obesity (BMI 30.0-) were significantly lower among the young, the highly educated and those who walked or bicycled to work among both men and women, but also among men who used public transportation.

Table 4 shows that the odds ratios of overweight + obesity among men who walked or bicycled remained significantly lower 
Table 3

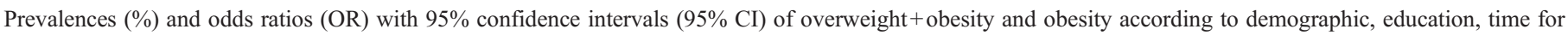
travel to work (one way) and means of transportation to work variables

\begin{tabular}{|c|c|c|c|c|}
\hline & \multicolumn{2}{|c|}{ Overweight + obesity } & \multicolumn{2}{|c|}{ Obesity } \\
\hline & $\%$ & OR $(95 \% \mathrm{CI})$ & $\%$ & OR $(95 \% \mathrm{CI})$ \\
\hline \multicolumn{5}{|l|}{ Age } \\
\hline $18-24$ & 21.2 & 1.00 & 5.4 & 1.00 \\
\hline $25-34$ & 30.9 & $1.67(1.31-2.12)$ & 10.4 & $2.03(1.33-3.10)$ \\
\hline $35-44$ & 35.3 & $2.03(1.61-2.57)$ & 10.4 & $2.03(1.34-3.08)$ \\
\hline $45-54$ & 39.2 & $2.40(1.90-3.04)$ & 10.7 & $2.10(1.38-3.19)$ \\
\hline $55-64$ & 45.1 & $3.07(2.42-3.89)$ & 10.8 & $2.12(1.39-3.23)$ \\
\hline $65-80$ & 51.2 & $3.92(2.40-6.39)$ & 18.8 & $4.05(2.04-8.04)$ \\
\hline (Missing) & $(220)$ & & $(220)$ & \\
\hline \multicolumn{5}{|l|}{ Country of origin } \\
\hline Sweden & 35.8 & 1.0 & 10.4 & 1.0 \\
\hline Other countries & 39.0 & $1.09(0.94-1.27)$ & 10.7 & $1.03(0.81-1.30)$ \\
\hline (Missing) & $(486)$ & & $(486)$ & \\
\hline \multicolumn{5}{|l|}{ Education } \\
\hline 13 years & 29.8 & 1.0 & 7.1 & 1.0 \\
\hline $10-12$ years & 35.9 & $1.32(1.17-1.49)$ & 10.2 & $1.48(1.21-1.81)$ \\
\hline-9 years & 46.2 & $2.03(1.82-2.25)$ & 14.5 & $2.22(1.87-2.63)$ \\
\hline (Missing) & $(973)$ & & $(973)$ & \\
\hline \multicolumn{5}{|c|}{ Time for travel to work (one way) } \\
\hline Less than $15 \mathrm{~min}$ & 37.0 & 1.00 & 10.7 & 1.00 \\
\hline 15 min or more & 37.0 & $0.99(0.90-1.13)$ & 9.9 & $0.91(0.81-1.09)$ \\
\hline (Missing) & $(996)$ & & $(996)$ & \\
\hline \multicolumn{5}{|l|}{ Means of transportation } \\
\hline Car & 38.3 & 1.00 & 10.4 & 1.00 \\
\hline Walking/bicycling & 32.7 & $0.82(0.74-0.91)$ & 8.7 & $0.79(0.66-0.94)$ \\
\hline Public transportation & 37.1 & $0.96(0.85-1.08)$ & 11.5 & $1.09(0.90-1.31)$ \\
\hline Other & 39.5 & $0.98(0.73-1.32)$ & 13.2 & $1.31(0.87-1.99)$ \\
\hline (Missing) & $(936)$ & & $(936)$ & \\
\hline
\end{tabular}

$N($ women $)=8750$.

The Public Health Survey in Skåne, 2004.

in all models, from 0.65 (95\% CI $0.57-0.73)$ in the age-adjusted model to $0.69(95 \%$ CI $0.60-0.79)$ in the model including all confounders, compared to the car driving reference category. The odds ratios of obesity among men were significantly lower in the walking and bicycling category in the age-adjusted as well as in the age- and country of origin-adjusted models but became not significant in the models also adjusted for education and time spent for travel to work. A significant and negative association between public transportation (bus and/or train) and overweight + obesity as well as obesity was observed among men throughout the multivariate analyses. The odds ratios of overweight + obesity as well as obesity remained significantly decreased for the walking and bicycling category among women when compared with car driving reference category. In contrast, the odds ratios of overweight + obesity as well as obesity in the public transportation category remained not significant compared to the car driving reference category among women. The association between "other" means of transportation and obesity remained not significant in all analyses among both men and women.

\section{Discussion}

The means used for transportation to work are significantly associated with overweight + obesity and obesity. The odds ratios of overweight + obesity among men and women who walked or bicycled were significantly lower compared to the car driving reference category and remained significant in the models including all confounders. The odds ratios of obesity were initially significantly lower among both men and women who walked or bicycled, but only among women in the final models. The odds ratios of overweight + obesity as well as obesity were also lower among men but not women who used public transportation.

The results of this study suggest that bicycling and/or walking to work promotes energy expenditure and decreases the risk of overweight + obesity and, to some extent, obesity. In contrast, public transportation is only significantly negatively associated with overweight + obesity and obesity among men compared to the car driving reference category. It may be that the lower proportion of men who use public transportation may be a more selected group with reference to health related diet, exercise behaviours and other health related behaviours than among women. Men on the labour market have job positions connected higher salaries than women (Lindström, 2000). People with lower socioeconomic status have an increased risk of obesity (Lindström, 2000), and it may be that the higher proportion of women that utilizes public transportation to work include women who can not afford a car. Still, the results imply that bicycling and walking but most probably also public transportation by bus and/or train to work should be promoted as potent preventive strategies.

Physical and social structural aspects should be considered when trying to understand why people use different means of 
Table 4

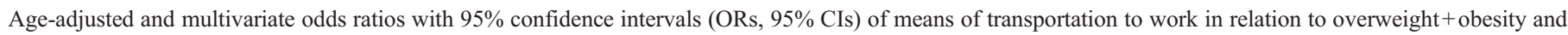
obesity

\begin{tabular}{|c|c|c|c|c|}
\hline \multicolumn{5}{|l|}{ Men } \\
\hline Overweight + obesity, means of transportation to work & OR $(95 \% \mathrm{CI})^{\mathrm{a}}$ & OR $(95 \% \mathrm{CI})^{\mathrm{b}}$ & OR $(95 \% \mathrm{CI})^{\mathrm{c}}$ & OR $(95 \% \mathrm{CI})^{\mathrm{d}}$ \\
\hline Car & 1.00 & 1.00 & 1.00 & 1.00 \\
\hline Walking/bicycling & $0.65(0.57-0.73)$ & $0.64(0.57-0.73)$ & $0.67(0.59-0.76)$ & $0.69(0.60-0.79)$ \\
\hline Public transportation & $0.63(0.54-0.74)$ & $0.63(0.54-0.74)$ & $0.70(0.59-0.82)$ & $0.72(0.61-0.86)$ \\
\hline Other & $0.79(0.61-1.03)$ & $0.79(0.61-1.03)$ & $0.86(0.65-1.13)$ & $0.96(0.70-1.30)$ \\
\hline Obesity, means of transportation to work & OR $(95 \% \mathrm{CI})^{\mathrm{a}}$ & OR $(95 \% \mathrm{CI})^{\mathrm{b}}$ & $\mathrm{OR}(95 \% \mathrm{CI})^{\mathrm{c}}$ & OR $(95 \% \mathrm{CI})^{\mathrm{d}}$ \\
\hline Car & 1.00 & 1.00 & 1.00 & 1.00 \\
\hline Walking/bicycling & $0.77(0.64-0.93)$ & $0.78(0.64-0.94)$ & $0.82(0.67-1.01)$ & $0.85(0.68-1.07)$ \\
\hline Public transportation & $0.59(0.45-0.78)$ & $0.60(0.46-0.79)$ & $0.67(0.50-0.90)$ & $0.70(0.51-0.95)$ \\
\hline Other & $0.80(0.53-1.19)$ & $0.81(0.54-1.21)$ & $0.96(0.63-1.45)$ & $1.01(0.66-1.61)$ \\
\hline \multicolumn{5}{|l|}{ Women } \\
\hline Overweight + obesity, means of transportation to work & OR $(95 \% \mathrm{CI})^{\mathrm{a}}$ & OR $(95 \% \mathrm{CI})^{\mathrm{b}}$ & OR $(95 \% \mathrm{CI})^{\mathrm{c}}$ & OR $(95 \% \mathrm{CI})^{\mathrm{d}}$ \\
\hline Car & 1.00 & 1.00 & 1.00 & 1.00 \\
\hline Walking/bicycling & $0.81(0.73-0.90)$ & $0.81(0.73-0.90)$ & $0.82(0.73-0.91)$ & $0.80(0.70-0.91)$ \\
\hline Public transportation & $0.98(0.87-1.11)$ & $0.97(0.86-1.10)$ & $1.00(0.88-1.14)$ & $1.01(0.87-1.17)$ \\
\hline Other & $0.89(0.67-1.20)$ & $0.90(0.67-1.21)$ & $0.91(0.66-1.25)$ & $0.93(0.65-1.34)$ \\
\hline Obesity, means of transportation to work & OR $(95 \% \mathrm{CI})^{\mathrm{a}}$ & OR $(95 \% \mathrm{CI})^{\mathrm{b}}$ & OR $(95 \% \mathrm{CI})^{\mathrm{c}}$ & OR $(95 \% \mathrm{CI})^{\mathrm{d}}$ \\
\hline Car & 1.00 & 1.00 & 1.00 & 1.00 \\
\hline Walking/bicycling & $0.78(0.66-0.93)$ & $0.77(0.65-0.92)$ & $0.77(0.64-0.94)$ & $0.81(0.66-0.99)$ \\
\hline Public transportation & $1.09(0.91-1.33)$ & $1.08(0.90-1.31)$ & $1.13(0.92-1.38)$ & $1.21(0.96-1.52)$ \\
\hline Other & $1.27(0.84-1.93)$ & $1.30(0.85-1.97)$ & $1.38(0.88-2.16)$ & $1.43(0.87-2.36)$ \\
\hline
\end{tabular}

The Public Health Survey in Skåne, 2004.

a Adjusted for age.

b Adjusted for age and country of origin.

c Adjusted for age, country of origin and education.

d Adjusted for age, country of origin, education and time for travel to work (one way).

transportation to work. Physical environments, e.g. access to pavements and green surroundings, are positively associated with exercise and physical activity in general (Humpel et al., 2002; Leyden, 2003; Wilson et al., 2004; van Lenthe et al., 2005). Neighbourhood-level social capital may also affect physical activity by mechanisms that entail the norms and values, trust between citizens as well as generalized reciprocity. Several US multilevel studies have documented associations between aspects of social capital and neighbourhood physical activity (Fisher et al., 2004; Greiner et al., 2004). Diet may also be influenced by physical and social characteristics of different areas such as varying prevalences of supermarkets and fast food restaurants (Morland et al., 2002) as well as varying relative costs of healthy compared to unhealthy food according to degree of neighbourhood deprivation (Sooman et al., 1993). It may be that urban areas, characterized by greater geographic proximity to work, may promote bicycling and walking to work. On the other hand, urbanized areas tend to have greater traffic volume and speed, which has been found to decrease the sense of comfort among cyclists (Harkey et al., 1998). The inclusion of environmental factors will most plausibly increase our understanding of bicycle use (de Bruijn et al., 2005) and walking for transportation to work. The availability of bus and train in different areas should also be considered.

Bicycling and walking to work are important aspects of leisure time physical activity because they are structural activities that recur every day of the work week. However, the question how respondents interpret items on leisure time physical activity in relation to the item concerning means of transportation to work remains open. Do respondents interpret bicycling or walking to work as an aspect of leisure time physical activity or not when they answer a questionnaire? An additional analysis (not included in tables) was conducted including leisure time physical activity (a four alternative item with alternatives ranging from completely sedentary life style to physical activity close to the elite level). However, the addition of this item did not affect the odds ratios.

Men born in other countries than Sweden have significantly higher odds ratios of overweight + obesity (BMI 25.0 or more). Similar results have been demonstrated in an earlier study (Lindström and Sundquist, 2005).

\section{Strengths and limitations}

The participation rate is $59 \%$ which is comparable to other recent investigations (Lindström, 2004). The study population shows a similar composition according to sociodemographic variables compared to the general composition of the population of Skåne in statistical registers. However, the group born in other countries than Sweden is under-represented by approximately 4 per cent units in this study compared to official register statistics for Skåne. Still, the risk of selection bias was considered low in a previous study on a random sample conducted with approximately the same sampling design and the same participation rate (59\%) in Skåne 2000 (Carlsson et al., 2006). 
Self-reported height and weight may introduce misclassification problems because weight might be underestimated by respondents with overweight or obesity. Respondents also tend to overestimate their height (Boström and Diderichsen, 1997). Such misclassification may have resulted in an underestimation of the prevalences of overweight and obesity in this study. Still, the prevalences of overweight and obesity are very similar to those found in the Swedish national public health report (National Public Health Report, 2005). The means of transportation variable has not been found to be misclassified to any important extent in other studies (Wen et al., 2006). The extent to which there is misclassification of BMI may vary between different categories of commuters. However, to our knowledge there is no previous reference that has either verified or falsified this notion.

The dichotomization of the time for travel to work (one way) variable into less than $15 \mathrm{~min}$ and $15 \mathrm{~min}$ or more is based on the fact that regular moderate physical activity such as for instance walking and bicycling $30 \mathrm{~min}$ a day or more in five or more days a week is the recommended level of exercise (US Department of Health and Human Services, 1990), and the notion that the major part of the health benefits will occur when adults with a sedentary lifestyle become moderately active (Haapanen et al., 1996).

Age, sex, country of origin, education and travel time to work might be confounders of the association between the means of transportation to work and overweight + obesity and obesity variables. Adjusting for these potential confounders and stratifying for sex produced no important change in the effect size associated with means of transportation to work and overweight + obesity and obesity.

The cross-sectional study design makes it impossible to draw inferences with certainty concerning direction of causality and causal pathways. However, it is probably not a serious weakness in this study, because the relationship between means of transportation to work and overweight + obesity and obesity is a matter that should be seriously considered regardless of direction of causality. The most likely direction of causality would plausibly be from means of transportation to work to overweight and obesity. However, this cross-sectional study should most importantly be regarded as an exploratory study of the association between means of transportation to work and overweight/obesity, not as an analytical study inferring conclusions concerning a specific direction of causality.

\section{Conclusion}

Means of transportation to work are significantly associated with overweight + obesity and with obesity. Particularly walking and bicycling to work is significantly negatively associated with overweight+obesity and, to some extent, obesity. Public transportation is also significantly negatively associated with overweight + obesity and obesity among men.

\section{Acknowledgments}

This study was funded by the Swedish ALF Governments Grant Dnr. M:B 39 921/2006 and the Research Funds of Malmö University Hospital.

\section{Appendix A}

Description of exact phrasing of variables:

BMI (body mass index) was calculated as $\mathrm{kg} / \mathrm{m}^{2}$ from self reported height ("What is your height (in $\mathrm{cm}$ )?") and weight ("What is your weight (in $\mathrm{kg}$ )?").

Modes of transportation category: The exact question is "How do you usually travel to work?" with the alternatives (1) walking, (2) bicycling, (3) car, (4) bus, (5) train and (6) other. The respondents were allowed to answer more than one alternative. If people responded only 1 or 2 or the combination of 1 and 2, then they belong to the "walking and/or bicycling" category. If people responded only 3 then they belong to the "car" category. If people responded 4 or 5 , or 4 and 5 , then they belong to the "public transportation/ bus and train" category. The "other" category in the final analysis thus includes not only those who answered 6, but also people answering any other combinations of alternatives. The "other" category is thus most plausibly not possible to interpret in any way. It is, on the other hand, a numerically very small group (3.1\% of men, $2.1 \%$ of women, $2.6 \%$ of all in this study).

Time for travel to work. "How long time does it take you to get to work (one way)?". Alternatives: (1) less than $15 \mathrm{~min}$, (2) 15-30 min, (3) 30-60 min, (4) 1-1.5 h, (5) 1.5-2 h, (6) more than $2 \mathrm{~h}$.

The exact phrasing of the leisure time physical activity question is "How many times have you exercised and exposed yourself to physical strain during the past twelve months?" with the response alternatives "Regular exercise and training" (running, swimming, tennis, badminton, gymnastics or similar on average at least three times a week, at least $30 \mathrm{~min}$ per occasion), "Moderate regular exercise during leisure time" (running, swimming, tennis, badminton or similar activity 1-2 times per week at least 30 min per occasion, and the activity makes you sweat), "Moderate exercise during leisure time" (walking, bicycling or other moderate physical activity at least $2 \mathrm{~h}$ a week without sweating. Garden work, fishing, table tennis and bowling may also be included) and "Sedentary leisure time" (reading, watching TV, cinema and other sedentary activities during leisure time. Walking, bicycling or similar activities less than $2 \mathrm{~h}$ a week).

\section{References}

Bell, A.C., Ge, K., Popkin, B.M., 2002. The road to obesity or the path to prevention: motorized transportation and obesity in China. Obes. Res. 10, 277-283.

Berrigan, D., Troiano, R.P., 2002. The association between urban form and physical activity in US adults. Am. J. Prev. Med. 23, 74-79.

Besser, L.M., Dannenberg, A.L., 2005. Walking to public transit: steps to help meet physical activity recommendations. Am. J. Prev. Med. 29 (4), 273-280.

Boström, G., Diderichsen, F., 1997. Socioeconomic differentials in misclassification of height, weight and body mass index based on questionnaire data. Int. J. Epidemiol. 26, 860-866.

Carlsson, F., Merlo, J., Lindström, M., Östergren, P.O., Lithman, T., 2006. Representativity of a postal questionnaire survey in Sweden, with special reference to ethnic differences in participation. Scand. J. Public Health 34 (2), 132-139. 
Craig, C.L., Brownson, R.C., Cragg, S.E., Dunn, A.L., 2002. Exploring the effect of the environment on physical activity: a study examining walking to work. Am. J. Prev. Med. 23, 36-43.

de Bruijn, G.J., Kremers, S.P.J., Schaalma, H., van Mechelen, W., Brug, J., 2005. Determinants of adolescent bicycle use for transportation and snacking behaviour. Prev. Med. 40, 658-667.

Eyler, A.A., Brownson, R.C., Bacak, S.J., Housemann, R.A., 2003. The epidemiology of walking for physical activity in the United States. Med. Sci. Sports Exerc. 35, 1529-1536.

Fisher, K.J., Li, F., Michael, Y., Cleveland, M., 2004. Neighborhood influences on physical activity among older adults: a multilevel analysis. J. Aging Phys. Act. 11, 45-63.

Flegal, K.M., Carroll, M.D., Ogden, C.L., Johnson, C.L., 2002. Prevalence and trends in obesity among US adults, 1999-2000. JAMA-J. Am. Med. Assoc. 288, 1723-1727.

Frank, L.D., 2000. Land use and transportation interactions: implications in public health and quality of life. J. Plann. Educ. 6-22.

Frank, L.D., Andresen, M.A., Schmid, T.L., 2004. Obesity relationships with community design, physical activity, and time spent in cars. Am. J. Prev. Med. 27, 87-96.

Gregg, E.W., Cheng, Y.J., Cadwell, B.L., et al., 2005. Secular trends in cardiovascular disease risk factors according to body mass index in US adults. JAMA — J. Am. Med. Assoc. 1868-1874.

Greiner, K.A., Chaoyang, L., Kawachi, I., Hunt, D.C., Ahluwalia, J.S., 2004. The relationships of social participation, and community ratings to health behaviors in areas with high and low population density. Soc. Sci. Med. 59, 2303-2312.

Haapanen, N., Miilunpalo, S., Vuori, I., Oja, P., Pasanen, M., 1996. Characteristics of leisure time physical activity associated with decreased risk of premature all-cause and cardiovascular disease mortality in middle-aged men. Am. J. Epidemiol. 143, 870-880.

Harkey, D., Reinfurt, D., Knuiman, M., Stewart, J., Sorton, A., 1998. Development of the Bicycle Compatibility Index: A Level of Service Concept, Final Report. University of North Carolina, Chapel Hill (NC).

Humpel, N., Owen, N., Leslie, E., 2002. Environmental factors associated with adults' participation in physical activity: a review. Am. J. Prev. Med. 22 (3), 188-199.

Leyden, K.M., 2003. Social capital and the built environment: the importance of walkable neighbourhoods. Soc. Sci. Med. 93 (9), 1546-1551.

Lindström, M., 2000. Social Participation, Social Capital and Socioeconomic Differences in Health Related Behaviours. An Epidemiological Study. Lund University, Malmö.
Lindström, M., Sundquist, K., 2005. The impact of country of birth, and time in Sweden on overweight and obesity: a population-based study. Scandinavian J. Public Health 33 (4), 276-284.

Lindström, M., Isacsson, S.O., Merlo, J., 2003. Increasing prevalence of overweight, obesity and physical inactivity during leisure time between 1986 and 1994 in Malmö, Sweden. Eur. J. Public Health 13, 306-312.

Lindström, M., 2004. Social capital, the miniaturization of community and self reported global and psychological health. Soc. Sci. Med. 59 (3), 595-607.

Lopez-Zetina, J., Lee, H., Friis, R., 2006. The link between obesity and the built environment. Evidence from an ecological analysis of obesity and vehicle miles of travel in California. Health Place 654-664.

Morland, K., Wing, S., Diez Roux, A., 2002. The contextual effect of the local food environment on resident's diets: the atherosclerosis risk in communities study. Am. J. Public Health 92, 1761-1767.

National Public Health Report, 2005. National Board on Health and Welfare, Stockholm.

Norusis, M.J., 2000. SPSS for Windows. Advanced Statistics. Release 10.0. SPSS, Chicago.

Saelens, B.E., Sallis, J.F., Frank, L.D., 2003. Environmental correlates of walking and bicycling: findings from the transportation, urban design, and planning literatures. Annals Behav. Med. 25, 80-91.

Sherwood, N.E., Jeffery, R.W., 2000. The behavioral determinants of exercise: implications for physical activity interventions. Annu. Rev. Nutr. 20, 21-44.

Sooman, A., MacIntyre, S., Anderson, A., 1993. Scotland's health-a more difficult challenge for some? The price and availability of healthy foods in socially contrasting localities in the west of Scotland. Health Bull. (Edinb.) $51,276-284$.

US Department of Health and Human Services, 1990. Healthy People 2000: National Health Promotion and Disease Prevention Objectives. US Government Printing Office, Washington, DC.

van Lenthe, F.J., Brug, J., Mackenbach, J.P., 2005. Neighbourhood inequalities in physical activity: the role of neighbourhood attractiveness, proximity to local facilities and safety in the Netherlands. Soc. Sci. Med. 60 (4), 763-775.

Wen, L.M., Orr, N., Millett, C., Rissel, C., 2006. Driving to work and overweight and obesity: findings from the 2003 New South Wales Health Survey, Australia. Int. J. Obes. 30 (5), 782-786.

Wilson, D.K., Kirtland, K.A., Ainsworth, B.E., Addy, C.L., 2004. Socioeconomic status and perceptions of access and safety for physical activity. Annals of Behav. Med. 28, 20-28.

Young, I.R., Nestle, M., 2002. The contribution of expanding portion sizes to the US obesity epidemic. Am. J. Public Health 92, 246-249. 